\title{
СОВРЕМЕННЫЙ РУССКО-КИТАЙСКИЙ СЛОВАРЬ В РОССИИ И КИТАЕ: СТРУКТУРА СЛОВАРНОЙ СТАТЬИ
}

\section{MODERN RUSSIAN-CHINESE DICTIONARY IN RUSSIA AND CHINA: STRUCTURE OF THE DICTIONARY ENTRY}

\section{Gao Yanjun}

Summary: The article compares two Russian-Chinese dictionaries created in Russia and China in the XXI century. Russian Russian - Chinese dictionary, edited By N. N. Voropaev, and "new Russian-Chinese dictionary" (new Russian-Chinese dictionary). The features of differences in the dictionary entries of these dictionaries are revealed and the reasons for this are shown.

Keywords: bilingual lexicography, Russian-Chinese dictionary, microstructure, dictionary entry, comparison.

\author{
Гао Яньцзюнь \\ Аспирант, Московский государственный университет \\ имени М.В. Ломоносова \\ yantszyun.gao@mail.ru
}

Аннотация: В статье проводится сравнение двух русско-китайских словарей, созданных в России и в Китае в XXI веке. Это - «Современный русско-китайский словарь» по ред. Н.Н. Воропаева и «新俄汉词典》 (Новый русскокитайский словарь). Выявляются черты различия в словарных статьях этих словарей и показывается то, чем это обусловлено

Ключевые слова: двуязычная лексикография, русско-китайский словарь, микроструктура, словарная статья, сравнение.
Д вуязычная, или переводная, лексикография насчитывает по меньшей мере четыре тысячелетия. В истории человечеством созданы тысячи переводных словарей. С расширением круга языков и увеличением количества словарей в XX веке, людьми был накоплен огромный практический опыт составления переводных словарей, но практический опыт переводной лексикографии доныне не имеет должного теоретического обоснования [1]. Появление теоретической двуязычной лексикографии сопровождается появлением теоретических обобщающих работ. Статья на слово «Лексикография» в ЛЭС указывает, что «Теоретическая лексикография сформировалась во 2-й трети 20 в. Первую научную типологию словарей создал советский учёный Л. В. Щерба (1940). Дальнейшее развитие она получила в трудах многих советских и зарубежных лингвистов (ЧССР, Франция, США и др.)» [2]. На основе этих теоретических обобщающих работ, таких как: «Опыт общей теории лексикографии» Л.В. Щербы, лексикографы продолжают свои исследования до настоящего времени и усовершенствуют теорию двуязычной лексикографии дальше.

Сопоставляемые однотомные русско-китайские словари - это опубликованный в 2012 г. издательством «Восточная книга» «Современный русско-китайский словарь» под редакцией Н.Н. Воропаева, и переизданный в 2007 г. издательством «Ляонин жэньминь чубаньшэ» 《新俄汉词典》 (Новый русско-китайский словарь), сопоставленный группой учёных факультета иностранных языков Ляонинского университета. По объёму словаря, существует небольшая разница между ними - русский словарь содержит около 40 тысяч лексических единиц и китайский словарь содержит 60 тысяч лексических единиц.

Как известно, состав частей речи в разных языках различен. Такие различия касаются как самого набора частей речи, так и объёма отдельных частей речи. В русском языке выделяются самостоятельные части речи (имя существительное, имя прилагательное, имя числительное, местоимение, глагол, наречие, предикатив, причастие и деепричастие), служебные части речи (предлог, союз и частица), модальные слова, и междометия. Согласно «现代汉语词典》 («Соварь современного китайского языка»), вышедшему в 2012 году в Китае, слова современного китайского языка разделились на двенадцать классов, именно «名词、动词、形容词、数词、 量词、代词、副词、介词、连词助词、叹词、拟声词。 其中名词、动词、形容词各有两个附类, 名词的附类是 时间词、方位词, 动词的附类是助动词、趋向动词, 形 容词的附类是属性词、状态词。代词分为三小类; 人称 代词、指示代词和疑问代词》 [5] ('имена существительные, глаголы, имена прилагательные, числительные, счетные слова, местоимения, наречия, предлоги, союзы, частицы, междометия и звукоподражательные слова. Среди них имени существительные, глаголы и имени прилагательные также имеют по два группы, это существительные-темпоративы, существительные-директивы, глагол направленности действия, вспомогательный глагол, атрибутивные прилагательные и предикативные 
прилагательные. Местоимения делятся на: личные местоимения, указательные местоимения и вопросительные местоимения').

Итак, в соответствии с классификацией частей речи во входном языке выбранных двуязычных словарей, а именно в русском языке, автор данной работы выбрал три представительных вида из самостоятельных частей речи, которые играют очень важную роль в русском языке.

Материалом для исследования послужили следующие статьи из русского и китайского двуязычных словарей с заглавными лексическими единицами-существительными (вид, вода, артист), прилагательными (весёлый, взрослый) и глаголами (владеть, ввести).

1. «вид I (1) внешность, видимый облик外表wàibiăo, 神态 shéntài; 外形 wàixíng, 状态 zhuàngtài; 景 象 jǐngxiàng; праздничный города 城市的节日景象 chéngshì de jiērì jǐngxiàng. (2) местность, видимая взором:пейзаж景物 jǐngwù; 风景画面 fēngjǐng huàmiàn; из окна 窗外的景色 chuāngwài de jǐngsè. (3) нахождение в поле зрения 视野 shìyě; 视力范围 shìli fànwéi; быть на у у всеx 在众目睽睽之下 zài zhòngmùkuíkuí zhīxià.

В Виде чего-л. 作为 zuòwéi; $\sim$ исключения 作为例 外 zuòwéi lìwà. Делать вид 假装 jiăzhuāng; он сделал ， что не узнал меня 他装作没认出我来 tā zhuāngzuò méi rènchū wǒ lái. Иметь в виду кого-что-л. 指的是 zhǐ de shì; 考虑到 kăo lǜ dào; я имел в у вас, когда говорил о новой работе 说那项新工作时, 我曾考虑到您 shuō nàxiàng xīngōngzuò shí, wǒcéng kăolǜ dào nín. Ни под каким видом 在任何情况下都不 zài rènhé qíngkuàng xià dōubú; не могу согласиться на это 在任何情况下我 都不会考虑这件事 zài rèn hé qíngkuàngxià wǒdōu búhuì kăolǜ zhèjiànshì. II. (1) подразделение в систематике 种 zhǒng, 种类 zhǒng lèi; новый работы 新的工种 xīnde gōngzhǒng; разные растений 植物的不同种类 zhíwù de bútóng zhǒnglèi. (2) (грамм.) глагольный 动词的体 dòngcí de ť̌; несовершенный 未完成体 wèi wánchéngtǐ; совершенный вид 完成体 wánchéngtĩ.» [Воропаев, 2012: 39] / «вид1, - $a$ 或-y, 单六 $0-e, 8-e, 8-y, н a-y$ [阳] (1) 外表, 外貌; 外观; 神态; 状态. вне́шний 外表. уста́лый 疲 惫的样子 $<\ldots>2$ (单六 $O-e, 8-e$ ) 眺望; 风景; 景色; 视力可以到达的地方; 风景画. ко́мната с ом на мо́ре 可 以眺望海上风景的房间. города 城市风光<... 3 (单

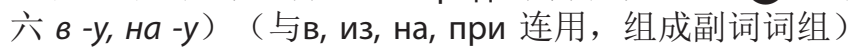
视野, 视阈 . скрыіться из а (或из виду) 4 (只用复) < 转> 企图, 打算; 预测, 预想. ы на будущее 对未来的 展望 $\diamond$ Вид на жительство <旧>身份证; 居留证 <...> всех на виду 在众目睽睽之下. » [新俄汉词典 2007: 150].

2. «вод|а (1) жидкость 水 shuі; пресная, морская, горячая 淡水 dànshu1̌, 海水 hăishuǐ, 热水 rèshuǐ; поливать цветы ой 用水浇花 yòng shuǐ jiāohuā. (2) напиток без алкоголя 不含酒精的饮料 bú hán jiǔjīng de

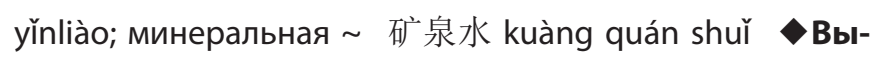
ходить сухим из воды 摆脱的干净 băituō de gànjìng. Тише воды, ниже травы 非常顺从 fēicháng shùncóng / водн|ый; ое пространство 水域 shulyù; спорт 水上运 动 shuľshàng yùndòng. » [Воропаев, 2012: 44] / «вода́, 单 四 во́ду, 复 во́ды [阴] 1 水. речна́я 河水. из колодцца 井 水 $<\ldots>2$ (常带定语) 饮料; （医疗、化妆等用的） 水溶液. газиро́ванная 汽水. минера́льная $\sim$ 矿泉水 3 (带定语, 只用复) принима́ть ы 洗矿泉. е́хать на ～去洗矿泉 4 (常用复) 大片的水; (江河湖海的) 水 流. весе́нние ы 春汛. подзе́мные ы 地下水 5 (只用 复) 水域, 海域, 近海. госуда́рственные ы 国家的水域 $<\ldots>\diamond$ Жёлтая вода́ 青光眼 <...> Как (бу́дто, словно) в воду опущенный 抑郁不欢的样子; 沮丧的样子.» [新 俄汉词典 2007: 171].

3. «артист 演员 yănyuán, 艺人 yìrén; известный 著 名演员 zhemíng yănyuán.» [Воропаев, 2012: 44] / «арти́cт [阳]演员, 艺人 (指戏剧演员、歌唱家、音乐家等). о́перный 歌剧演员. цирковой 杂技演员. заслу́женный $\sim$ 功勋演员. кино 电影演员 $\|$ арти́стка [阴] 》[ 新俄汉词 典 2007: 108].

4. «весёл|ый (1) полный веселья 快乐的 kuàilè de, 愉快的 yú kuài de, 开心的 kāixīn de, 欢乐的 huānlè de; она была a 她很快乐 tā hěn kuàilè. (2) доставляющий веселье 使人开心的 shǐrén kāixīn de, 有趣的 yǒu qù de; ая комедия 有趣的喜剧 yǒuqùde xĭjù / весело; он смеялся 他开心地笑了 tā kāixīn dì xiàole; на вечеpe было 晚会上充满了欢乐 wănhuìshàng chōngmănle huānlè.» [Воропаев, 2012: 36] / «весёлый, ве́сел, -а́, ве́село [形]1 快活的, 快乐的; 轻松愉快的. челове́к 快活的 人. ое настрое́ние 愉快的心情. ая атмосфе́ра 欢乐的气 氛. ая ульбка 愉快的微笑. 2 (只用全) 令人欢乐的, 有 趣的. спекта́кль 令人开心的戏. ая шуттка 有趣的笑话. пра́здник 愉快的节日» [新俄汉词典 2007: 135].

5. «взросл|ый 成年的 chéngniánde; сын 成年的儿子 chéngnián de érzǐ; стать ым 成年了 chéngnián le; взрослые (в знач. сущ.; npomuвon. demu) 大人dàrén; слушаться ых 听大人的话 tīng dàrén de huà.» [Воропаев, 2012: 38] / «взрослый -сел 或-сл -ла; -ле́е [形] 1 成年的. ая дочь 成年的女儿. 2 (只用全) $<$ 口 供成年人使用的. ая книга 成人书籍. 3 (用作名) взро́слый, -ого [阳] взро́слая, -ой [阴] 成年人, 大人 || взро́слость [阴]»[新俄汉词典 2007: 148].

6. «владеть (1) иметь собственность 有 yǒu, 占有 zhànyǒu, 拥有 yōngyǒu; имущество, дачей, машиной 拥有财产 yōngyǒu cáichăn, 拥有别墅 yōngyǒu biéshù, 拥有汽车 yōngyǒu qìchē. (2) уметь пользоваться чем-л. 会使用 huì shǐyòng, 精通 jīngtōng, 掌握 zhăngwò; иностранными языками 掌握外语 zhăngwò wàiyŭ.» [Воропаев, 2012: 42] / «владе́ть, -е́ю, -е́шь [未] 1 кемчем 有, 占有. конём 有一匹马. имущщество 有财产. сре́дствами произво́дства 占有生产资料. 2 чем <转>具 
有. музыка́льным тала́нтом 具有音乐才能. 3 кем-чем 统治; 支配. <转> 掌握. высото́й 占领高地. судьбо́й 掌握命运. аудито́рией 能吸引住听众. внима́ние уче́бников 善于集中学生的注意力. (4 чем 会, 能; 精通. иглой 会使针. ме́тодами диалектичческого материа́ла 能运用辩证唯物主义. 5 y $\mathrm{em}$ 能使用、运用 (身体器官 等). не ле́вой ного́й 不会使用左腿 $\|$ владе́ние [中] $\diamond$ Владе́ть собо́й 控制自己. Владе́ть перо́м 擅长写作》 [新俄汉词典 2007: 161].

7. «ввести 引入 yǐnrù, 倒入 dǎorù, 推行 tuīháng, 采用 căiyòng; комендантский час 戒严 jièyán, 实行 宵禁 shíháng xiāojìn. 》 [Воропаев, 2012: 34] / «ввести, -еду́, -едёшь; ввёл, -ела́; -е́дший; -едённый (-ён, -ена́) [完] вводить, -ожу́, -одишь [末]1 кого-что 引入, 领进; 牵 入; 领上. го́стя в ко́мнату 把客人领进屋. лошаде́й в коню́шню 把马牵入马厩. 2 кого-что о что 使列入; 投 入. (кого) в соста́в делега́ции 把...列入代表权成员. （кого） в семью 把...纳入家庭成员. 34 что во что 注 入; 放进; 输入. лека́рство в ве́ну 把药物注入静脉. (4) 4то 建立; 规定, 制定. суро́вую дисципли́ну 规定严格 的纪律. но́вую мето́дику препода́вания 采用新的教学 法||введе́ние [中]. $\diamond$ Ввести́ во владе́ние 使正式取得 所有权. Ввести́ в курс де́ла 使了解. 》[新俄汉词典 2007: 120].

После вступления в XXI век, китайские и русские специалисты обратили большое внимание на полезности словарей для пользователей своей страны, в связи с этим, словарные статьи в русско-китайских словарях, которые создаются как в России, так и в Китае, приобретают все больше различий. Следует отметить, что необходим подробный анализ данных различий, чтобы можно было обобщить особенности лексикографии разных поколений.

Во-первых, грамматическая информация в словарях различается:

а) в китайском словаре, в отличии от русского, в случае если возникают сложности при определении некоторых падежей, всегда указываются падежные окончании («вид1, - $a$ 或-y, 单六 $0-e, 8-e, 8-y$, нa -y<...)》 [新俄汉 词典 2007: 150]).

В русском языке все существительные, имеющие форму единственного числа, обладают категорией рода. А в китайском языке имя существительное определяется только физиологически у человека, а у предметов и даже животных отсутствует категория рода. Поэтому при изучении русского языка для китайцев очень важно и необходимо различать постоянный признак существительного - род. В китайском словаре составители специально указывают род заглавного слова-существительного, который пишется на китайском языке и заключается в квадратные скобки («арти́ст [阳] <...> || арти́стка [阴]» '«арти'ст [мужской род] <...> || арти́стка [женский род]»'[ 新俄汉词典 2007: 108]). б) в отличии от русского словаря, в китайском словаре в случае, если заголовочной единицей является глагол, всегда указываются его окончания в первом и втором лице единственного числа настоящего времени. Если образование причастия или форма прошедшего времени от данного глагола может вызвать затруднение, то указывается его окончание. Далее указывается вид глагола на китайском языке в сокращенной форме и выделяется квадратными скобками («ввести, -еду́, -едёшь; ввёл, -ела́; -е́дший; -едённый (-ён, -ена́) [完] <...>» '«ввести, -еду́, -едёшь; ввёл, -ела́; -е́дший; -едённый (-ён, -ена́) [совершенный вид] <...>»'[新俄汉词典 2007: 120]).

в) в китайском словаре в том случае, когда заголовочной единицей является прилагательное, ударение его начальной, краткой и формы в сравнительной степени не совпадают, то указываются окончания этих форм. К примеру, «взросллый -сел 或-сл -ла; -ле́е, <...>» [新俄汉词典 2007: 148]. Составители указывают окончания краткой формы «взро́слого» (-сел или-сл, -ла) и окончание сравнительной степени (-ле́е), потому что их ударения не совпадают.

Во-вторых, существует большая разница в указании производного слова: В китайском словаре в случае, если заглавное слово является прилагательным или глаголом, то в словарной статье будет указано его существительное, образованное от заглавной единицы, отделенное знаком «\|» («ввести, <...> ||введе́ние [中] <...>» [新俄汉词典 2007: 120]; «взросслый <...> || взро́слость [ 阴]» [新俄汉词典 2007: 148]). А для заглавного слова-существительного мужского рода, обозначающих лицо по профессии, занимаемой должности и т. д., также в конце статьи указываются относительные формы женского рода («арти́ст <..> || арти́стка [阴]»[新俄汉词典 2007: 108]).

В русском словаре, как правило, указываются наречия, образованные от прилагательных и прилагательные, образованные от существительных, которые отделяются знаком «/» («весёл|ый <...> / весело; <...>» [Воропаев, 2012: 36]; «вод|а (1) <...> /водн|ый <...>» [Воропаев, 2012: 44]).

Третьим различием является то, что в словарных статьях русского языка всегда указывается транскрипция пиньинь («ввести 引入 yǐnrù, 倒入 dăorù <...> 实行宵 禁 shíháng xiāojìn.» [Воропаев 2012: 34]).

Четвёртое отличие - стилистические пометы. В китайском словаре пометы пишутся на китайском и выделяются угловыми скобками. В русских словарях пометы пишутся курсивом и выделяются круглыми скобками («вид < .. > (грамм.) глагольный <...>» [Воропаев, 2012: 39] / «вид1, $\diamond$ Вид на жительство <旧>身份证; 居留证 $<\ldots>$ »'«вид1, $\diamond$ Вид на жительство <старое слово> удостоверение личности; вид на жительство <...>»' [新 
俄汉词典 2007: 150).

Пятое различие - в отличие от китайского словаря, в словарных статьях русского словаря указываются синонимы, которые пишутся курсивом, после чего следует их китайский перевод («вод|a (1) жидкость 水 shuĭ; <...> (2) местность, видимая взором: пейзаж <...>» [Воропаев, 2012: 39]).

Шестое различие состоит в том, что словарная статья русского и китайского словаря отличается друг от друга в типографском оформлении:

а) в отличие от китайского словаря, в русском словаре ударение заголовочной единицы не указывается («владеть <...>» [Воропаев, 2012: 42]/ «владе́ть, <...>» [新俄汉词典 2007: 161]);

б) в русском словаре неизменяемая и изменяемая часть слова разделяются знаком «|». В китайских словарях разделение частей слова не предусмотрено («взросл|ый, <...>» [Воропаев, 2012: 38] / «взро́слый $<\ldots>$ » [新俄汉词典 2007: 148]);

в) в словарной статье русского словаря перед идиоматическими выражениями с толкуемой лексической единицей ставится знак «», а в китайском словаре ставится «॰» («вод|а (1) жидкость <...> Выходить су- хим из воды < ... >» [Воропаев, 2012: 44] / «вода́, < .. > $>$ Жёлтая вода́ <...>» [新俄汉词典 2007: 171]);

г) в словарной статье китайского словаря каждое значение в толковании обозначается арабскими цифрами, написанными стандартным шрифтом (1 ... 2 ... <..>). В русском словаре используется полужирный шрифт (1)...(2)...(3)... <...>) («владеть (1) иметь собственность <...> (2) уметь пользоваться чем-л. <..>» [Воропаев, 2012: 42] / «владе́ть, -е́ю, -е́шь [未] 1 кем-чем <..> (2) чем <转>具有 <...>» [新俄汉词典 2007: 161];

д) в русском словаре омонимы входят в состав словарной статьи и обозначаются римскими цифрами (I, II, III). В китайских словарях омонимы выделяются как отдельные заголовочные единицы и обозначаются арабскими цифрами в степени (а1, а2, а3) («вид)

(1) внешность, видимый облик <...> II. (1) подразделение в систематике <...>» [Воропаев, 2012: 39] / «вид1, <...>» [新俄汉词典 2007: 150]).

Итак, сопоставление современных русско-китайских словарей, изданных в России и Китае, выявило, что ориентация составителя / автора словаря на русского или китайского пользователя приводит к тому, что в русских и китайских статьях с одним и тем заголовочным словом имеются существенные различия.

\section{ЛИТЕРАТУРА}

1. Берков В.П. Вопросы двуязычной лексикографии (словник). Л.: Издательство Ленинградского университета, 1973. — 190 с.

2. Гак В.Г. Лексикография// Лингвистический энциклопедический словарь. - М.: Советская энциклопедия, 1990. - С. $258-259$.

3. Современный русско-китайский словарь / Н.Н. Воропаев, Ма Тяньюй, Дэн Цзе, С.М. Иванов. - М.: Восточная книга, 2012. - 384с.

4. 新俄汉词典：增订版/辽宁大学外语系《新俄汉词典》（增订版）编写组编写.一沈阳：辽宁人民出版社，2007（Новый русско-китайский словарь / Подготовлен группой по составлению «Нового русско-китайского словаря» (издание пересмотрено и дополнено) в институте иностранных языков Ляонинского университета. Шеньян: Ляонин жэньминь чубаньшэ, 2007.

5. 现代汉语词典 (6版) / 中国社会科学院语言研究所词典编辑室// 北京：商务印书馆, 2012. 1789 页 (Словарь современного китайского языка (6-е изд.). - Пекин: Шанъу иньшугуань, 2012. - 1789 с.) 